\title{
An Interesting Case of Polyuria in a Child
}

\author{
Arabinda Mohan Bhattarai ${ }^{1} \cdot$ Arun Sharma $^{2} \cdot$ Sulochana Parajuli $^{3} \cdot$ \\ Suju Mool ${ }^{4}$
}

Received: 27 July 2017/Accepted: 8 December 2017/Published online: 19 December 2017

(C) Association of Clinical Biochemists of India 2017

\begin{abstract}
A 1 year old male child with increased frequency of urine associated with increased thirst was found to have some developmental delays. Laboratory investigations showed increased serum sodium level and serum osmolality with decreased urine osmolality. An empty sella turcica was seen in contrast brain MRI; however focal demyelinating lesion was not present. He was managed with intranasal desmopressin therapy. Developmental delays in such cases can be prevented by early referral to a tertiary health care center where laboratory and imaging facilities are available.
\end{abstract}

Keywords Arginine vasopressin - Hypernatremia . Desmopressin · Diabetes insipidus · Osmolality · Water balance

\section{Case Description}

A 1 year old male child presented at pediatric OPD of a tertiary health care center with the chief complaints of increased frequency of urination, moderate in amount, clear and associated with increased thirst since 6 months of age. He was delivered institutionally via lower segment cesarean section (LSCS) and had a history of birth

Arabinda Mohan Bhattarai

arabinda.bhattarai@gmail.com

1 Department of Biochemistry, Nepal Army Institute of Health Sciences, Kathmandu, Nepal

2 Department of Pediatrics, Institute of Medicine, Tribhuvan University, Kathmandu, Nepal

3 Gandaki Medical College, Pokhara, Nepal

4 Nepal Army Institute of Health Sciences, Kathmandu, Nepal asphyxia with early onset neonatal sepsis; however the blood culture was negative. He had a head circumference, body weight and height at birth of $45 \mathrm{~cm}, 3.1 \mathrm{~kg}$ and $34 \mathrm{~cm}$ respectively. His head circumference, body weight and height at presentation were $45 \mathrm{~cm}$ (50th percentile), $10 \mathrm{~kg}$ (25th percentile) and $75 \mathrm{~cm}$ (90th percentile) respectively. He had few developmental delays with inability to sit without support and make double syllabic sounds.

On examination his pulse was 124 beats/min (80-130), respiratory rate was 31 per min (30-60) and blood pressure in right arm supine position was 90/40 mm Hg (72-104/ $37-56 \mathrm{mmHg}$ ). His laboratory results were as shown in Table 1.

We performed abdominal and skull X-ray; however the findings were non-significant. Contrast MRI of brain showed empty sella turcica with normal pituitary stalk and no signs of demyelination was seen.

\section{Results}

The laboratory findings were plasma sodium level $157 \mathrm{meq} / \mathrm{L}$ (135-145 meq/L), urine output $5 \mathrm{~mL} / \mathrm{kg} / \mathrm{h}$ $(2 \mathrm{~mL} / \mathrm{kg} / \mathrm{h})$, plasma osmolality $312 \mathrm{mOsm} / \mathrm{kg}$ $(275-295 \mathrm{mOsm} / \mathrm{kg})$ and urine osmolality $256 \mathrm{mOsm} / \mathrm{kg}$ (300-900 mOsm $/ \mathrm{kg}$ ). A complete physical examination was done to elicit the signs and symptoms of hypopituitarism. The anterior and posterior fontanelles were closed and the head circumference was normal for age. There was no any visible goiter or palpable edema in the body. Thyroid hormone profile showed normal TSH level $7.3 \mathrm{mU} / \mathrm{L}(0.96-13.68 \mathrm{mI} / \mathrm{L})$, Thyroxine (T4) $12.6 \mathrm{pmol} / \mathrm{L}$ (11.5-22.7 pmol/L) and T3 $13.5 \mathrm{pmol} / \mathrm{L}(11.5-22.7 \mathrm{pmol} /$ 
Table 1 Laboratory reports

\begin{tabular}{llc}
\hline Parameter & Patient & Reference \\
\hline Random blood glucose $(\mathrm{mmol} / \mathrm{L})$ & 6 & $3.8-7.8$ \\
Total leucocyte count $\left(\right.$ per $\left.\mathrm{mm}^{3}\right)$ & 11,800 & $4000-11,000$ \\
Hemoglobin $(\mathrm{gm} / \mathrm{dL})$ & 11.8 & $11-14$ \\
ESR in 1st hour Wintrobe's $(\mathrm{mm})$ & 12 & $0-13$ \\
MCV $(\%)$ & 72.4 & $70-84$ \\
Serum Sodium $(\mathrm{mmol} / \mathrm{L})$ & 163 & $138-145$ \\
Serum Calcium $(\mathrm{mmol} / \mathrm{L})$ & 2.27 & $2.20-2.65$ \\
Serum Osmolality $(\mathrm{mOsm} / \mathrm{kg})$ & 346 & $275-295$ \\
Urine Osmolality $(\mathrm{mOsm} / \mathrm{kg})$ & 256 & $300-900$ \\
Urine specific gravity & 1.005 & $1.002-1.006$ \\
BUN (mmol/L) & 4 & $1.8-6.0$ \\
Serum creatinine $(\mu \mathrm{mol} / \mathrm{L})$ & 31 & $17.7-53.0$ \\
Urine output $(\mathrm{mL} / \mathrm{h})$ & 41 & $20.8-25$ \\
\hline
\end{tabular}

L). Acquired infectious conditions like Toxoplasmosis, Rubella and Cytomegalovirus were ruled out by TORCH screening.

The urine osmolality and specific gravity 6-h after fluid deprivation were $265 \mathrm{mOsm} / \mathrm{Kg}$ and 1.003 respectively, thus the diagnosis of Diabetes Insipidus (DI) was made. Desmopressin challenge test was performed to differentiate central DI from nephrogenic DI. Intranasal $20 \mu \mathrm{g}$ desmopressin was administered and resolution of hypernatremia and hyposthenuria ensued as urine osmolality improved from 204 to $442 \mathrm{mOsm} / \mathrm{kg}$ after an hour of test. A preliminary diagnosis of neurogenic diabetes insipidus was made and intranasal desmopressin $10 \mu \mathrm{g}$ twice a day was started

We measured serum cortisol and ACTH in fasting AM state since DI can be masked by simultaneous cortisol deficiency and diuresis is seen only after the replacement therapy. The serum ACTH and cortisol were $5.5 \mathrm{pmol} / \mathrm{L}$ (2-11 pmol/L) and $>30 \mathrm{nmol} / \mathrm{L}$ respectively (Fig. 1).

On the next morning, he developed an episode of generalized tonic clonic seizure with decreased serum sodium level $(128 \mathrm{meq} / \mathrm{L})$. He was managed with $85.6 \mathrm{meq} / \mathrm{L}$ of sodium and chloride, $50 \mathrm{~g} / \mathrm{L}$ of glucose and $10 \mathrm{mEq}$ of $\mathrm{KCL}$ in $700 \mathrm{~mL}$ of NS intravenously over $48 \mathrm{~h}$.

\section{Discussion}

Diabetes Insipidus results from the lack of Antidiuretic hormone $(\mathrm{ADH})$, secreted from neurohypophysis. Its secretion is modulated by changes in the serum osmolality and by alterations in intravascular volume. If secretion or action of ADH falls below $80-85 \%$ of normal, urine concentration ceases and urine output is raised [1]. A small $(1-2 \%)$ decrease in body water and increase in plasma osmolality stimulate thirst and water intake is increased.

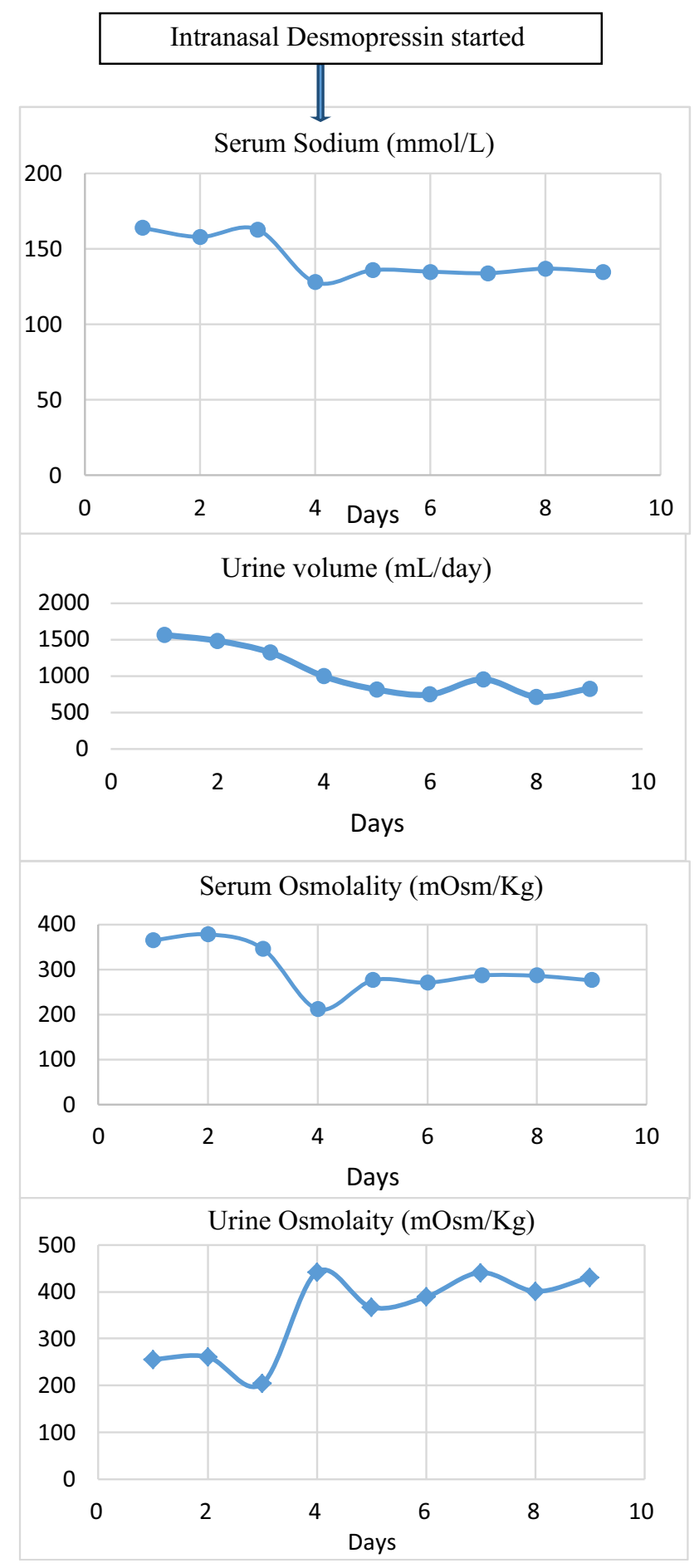

Fig. 1 Effects of desmopressin on water balance in the body

Overt physical or laboratory signs of dehydration do not develop unless the patient also has a defect in thirst or fails to drink for some other reason [2]. Desmopressin (DDAVP), a synthetic analogue of ADH acts selectively at V2 receptors (V2R) with the Gs signaling pathway via cAMP to increase urine concentration and decrease urinary flow in a dose dependent manner [3]. 
The electrolyte replacement in chronic hyponatremia should be done gradually as during the period of hyponatremia, concentration of intracellular charged protein moieties is altered and reversal cannot keep pace with the rapid correction of electrolyte status [4]. The central pontine myelinosis is a non inflammatory, symmetric demylinating lesion seen within the central basis pontis when hyponatremia is rapidly corrected [5].

The Empty Sella (ES) with normal pituitary stalk seen in MRI brain implicates normal pituitary functioning as it is an anatomical condition characterized by the presence of cerebrospinal fluid within the sella with a small pituitary gland compressed to the most caudal and dorsal aspect of the sella, thus creating the illusion of an 'empty sella' [6]. This condition is defined as primary (PES) when the patient had no history of pathological processes or previous pituitary surgery, radiotherapy or apoplexy [7].

Birth asphyxia (23\%) is a major cause of neonatal deaths worldwide and a major cause of neurological damage [8]. In a similar retrospective case study by $\mathrm{Su}$ et al. [9] the mean interval from neonatal hypoxic insult to the onset of DI was found to be 4 days and could vary from $2 \mathrm{~h}$ to 130 days; 10 patients (86\%) developed DI within 6 days after the hypoxic insults. In our case unawareness of symptoms and delay in health seeking behavior led to delay in presentation to the health care facility.

There is late health seeking behavior in situation such as ours where availability of resources and education level of general population is poor. The child presented only when symptoms worsened and developmental delays become prominent. It is possible that earlier presentation and diagnosis could prevent developmental delays in posture and speech. Thus, early referral to a tertiary center where lab and imaging facilities are available is important in such cases.

Chronic hypernatremia should be corrected slowly since hypernatremic dehydration results in severe hyperosmolality and sudden decrease in osmolality increases the risk of seizures due to brain edema and ideally should be managed in an ICU setup. As strict monitoring of fluid administration for $48 \mathrm{~h}$ is required, we failed to prevent seizure due to lack pediatric ICU in our centre. It's also a matter of concern for us about home management of this case as once discharged he will require regular desmopressin supplementation.

\section{Things to Remember}

a. The signs and symptoms of uncontrolled pituitary DI can be eliminated completely with desmopressin.

b. Chronic hypernatremia should be corrected more slowly due to the risks of brain edema during treatment.

c. ADH secretion is modulated by changes in the serum osmolality and by alterations in intravascular volume.

d. Child with polyuria and polydipsia should be referred early to the health care center to prevent developmental delays.

\section{Compliance with Ethical Standards}

Conflicts of interest The authors declare that they have no conflict of interest.

\section{References}

1. Kasper D, Fauci A, Hauser S, Longo D, Jameson JL, Loscalzo J. Harrison's principles of internal medicine. vol 2. Disorders of neurohypophysis. New York: McGraw-Hill; 2012. p. 2098-9.

2. McPherson RA, Pincus MR. Henry's clinical diagnosis and management by laboratory methods. Evaluation of renal Function, water, electrolytes and acid-base function. Missouri: Elsevier; 2012. p. 183-5.

3. Thornton SN. Thirst and hydration: physiology and consequences of dysfunction. Physiol Behav. 2010;100:15-21.

4. Singh TD, Fugate JE, Rabinstein AA. Central pontine and extrapontinemyelinolysis: a systematic review. Eur J Neurol. 2014;21:1443-50.

5. Khare SK. Neurohypophyseal dysfunction following perinatal asphyxia. J Pediatr. 1977;90:628-9.

6. ColmCostigan D, Daneman D, Harwood-Nash D, Holland FJ. The" empty sella" in childhood. Clin Pediatr. 1984;23:437-40.

7. Shalak L, Perlman JM. Hypoxic-ischemic brain injury in the term infant-current concepts. Early Hum Dev. 2004;80:125-41.

8. Root AW, Martinez CR. Magnetic resonance imaging in patients with hypopituitarism. Trends Endocrinol Metab. 1992;3:283-7.

9. Su DH, Liao KM, Chen HW, Huang TS. Hypopituitarism: a sequela of severe hypoxic encephalopathy. J Formos Med Assoc. 2006;105:536-41. 